\title{
Development of polyvalent toxoid Clostridium perfringens against anaerobic enterotoxaemia in young cattle and small ruminants
}

\author{
F.Kh. Pulotov ${ }^{1,2}$, O.D. Nazarova ${ }^{1, *}$, N.A. Akhmadov ${ }^{1}$, and A.I. Karimzoda ${ }^{2}$ \\ ${ }^{1}$ Institute for Problems Biological Safety and Biotechnology, Tajik Academy of Agricultural \\ Sciences, Dushanbe, Republic of Tajikistan \\ ${ }^{2}$ Tajik National University, Dushanbe, Republic of Tajikistan
}

\begin{abstract}
The authors of the article presents the results of the development of a polyvalent toxoid from C.perfringens strains against anaerobic enterotoxaemia of young cattle and small ruminants and an assessment of its effectiveness. It is presented the data on the selection of the recipe composition of the nutrient medium, the cultivation of industrial strains, the process of drug preparation, the selection of the optimal ratio of components and the method of controlling the effectiveness. Sequential cultivation of industrial strains of C.perfringens was carried out by cultivating them in flasks, bottles and bioreactors in the nutrient medium developed by the authors, consisting of: $12.0 \mathrm{~g} / 1$ - liver extract; $25.0 \mathrm{~g} / \mathrm{l}$ casein-peptone; $3.2 \mathrm{~g} / 1-\mathrm{K}_{2} \mathrm{HPO}_{4} ; 1.8 \mathrm{~g} / 1-\mathrm{KH}_{2} \mathrm{PO}_{4} ; 0.5 \mathrm{~g} / 1-\mathrm{MgSO}_{4}$. The development of the drug included the selection of optimal and balanced ratios of C. perfringens type A toxoids - $15 \mathrm{IU} / \mathrm{ml}$, C.perfringens type B $20 \mathrm{IU} / \mathrm{ml}$, C.perfringens type $\mathrm{C}-30 \mathrm{IU} / \mathrm{ml}, C$. perfringens type D - 30 $\mathrm{IU} / \mathrm{ml}$, which ensured $100 \%$ protection of the immunized animals. Studies on laboratory and farm animals revealed the harmlessness, areactogenicity of the drug, which stimulated the development of immunity and resistance to the toxic effects of all strains of C.perfringens.
\end{abstract}

\section{Introduction}

Anaerobic enterotoxaemia in cattle and small ruminants, as one of the infectious diseases of animals, is widespread in many foreign countries and in Russia, and it requires specialists in the field of modern biotechnology and veterinary medicine to develop and introduce into practice new effective drugs for its prevention [5,4]. The nature of the indicated anaerobic toxicoinfection has an acute course, in which the entire gastrointestinal tract is upset, which leads to intoxication of the body as a whole, the kidneys and the nervous system are affected $[6,11]$. The causative agents of anaerobic enterotoxemia are the bacteria Clostridium perfringens, which are widespread in the environment. They are defined as large, immovable, anaerobic, spore-forming, gram-positive rods [15-16].

Analysis of the scientific literature shows that the causative agents of the disease are bacteria C.perfringens of types A, B, C, D, F, rarely E, the differences of which are

\footnotetext{
* Corresponding author: orzugul@mail.ru
} 
associated with the secreted toxins and antigenic structure. It is noted that young farm animals (calves, pigs, lambs) are affected by gas gangrene, malignant edema, enterotoxaemia caused by serotype A; hemorrhagic enterotoxaemia - serotype $C$; enterotoxaemia of these animals and kids - serotype D; lambs with serotype B develop anaerobic dysentery; enterotoxaemia in calves is caused by serotype $\mathrm{E}$; and blue foxes develop enterotoxaemia caused by serotype $\mathrm{F}[6,9,13,20-21]$.

Infectious anaerobic enterotoxaemia has a significant spread in the Republic of Tajikistan, and as one of the diseases from the group of clostridiosis, it causes significant damage to the livestock industry. Bacteriological studies to determine the causative agents of anaerobic enterotoxaemia in the Republic of Tajikistan revealed that the most etiologically significant is C.perfringens types A, B, C, D [2,13-14].

The key role in the pathogenesis of anaerobic enterotoxaemia belongs to exotoxins, which, when ingested by agricultural animals, have a high reproductive activity, as a result of which an intensive process of disease development is observed. It should be noted that even early measures taken do not always lead to recovery. In this regard, the use of specific vaccine prophylaxis is considered the only effective method against clostridiosis $[3,8,14]$.

At the same time, the establishment of reasonable doses of components that promote stable immunity and its duration are a prerequisite for effective immunization of animals against anaerobic infection $[1,6,14]$. Since the pathogenicity and toxigenicity of different types of clostridia differ, the best prophylactic effect is manifested when using associated and polyvalent drugs $[13,10,18]$.

Despite the successes achieved, both in the study of the distribution, seasonality and stationarity of clostridiosis, and the existing developments in the field of preventive and veterinary-sanitary measures, there are significant losses of agricultural animals from these infections, which negatively affect the economic indicators of livestock farms $[7,14,19]$.

Until now, issues related to the development of effective measures against anaerobic infections of agricultural animals do not lose their relevance and have scientific and practical significance.

The aim of the study was to obtain a multicomponent C.perfringens toxoid against anaerobic enterotoxaemia in young cattle and small ruminants. In order to implement the set tasks of the study, a special nutrient medium was developed, a modern technology for the cultivation of industrial strains, as well as the best component combination with an effective dosage of strains, was developed.

\section{Material and methods}

Experimental test of the study were carried out in the Biotechnological complex of LLC "AGROVET" and the Institute for Problems of Biological Safety and Biotechnology TAAS [13]. During the research, we used production and control strains that were provided from the collection of AGROVET LLC, C.perfringens type A - 28, C.perfringens type B - 1, C.perfringens type C - 3, C.perfringens type D - 91. The development of a nutrient medium based on liver extract (Hungary) and casein-peptone (Italy), the following composition (g/l): liver extract - 12.0; casein-peptone - 25.0; $\mathrm{K}_{2} \mathrm{NPO}_{4}$ - 3.2; $\mathrm{KH}_{2} \mathrm{PO}_{4}-1.8 ; \mathrm{MgSO}_{4}$ - 0.5.

The method of sequential cultivation of production strains of C.perfringens in test tubes, vials, bottles and bioreactors was used. A bioreactor was used for industrial cultivation, in which there was a control system that regulates the main parameters, such as temperature conditions, $\mathrm{pH}$ level, stirrer speed. In this case, a deep method was used, at a temperature of $37 \pm 1{ }^{\circ} \mathrm{C}$, and chemically pure nitrogen was also supplied $\left(0.2-0.3 \mathrm{dm}^{3}\right.$ per $1 \mathrm{dm}^{3}$ of the medium in the reactor) [14].

The microscope was used to control the morphology of cells and their bacteriological purity. According to the optical bacterial standard name L.A. Tarasevich, the number of 
microbial cells per $1 \mathrm{~cm}^{3}$ of suspension was set. White mice were used to identify the general toxicity of microbial cultures and its degree, the mass of which ranged from 16 to $18 \mathrm{~g}$. Formalin was used to inactivate toxins; to concentrate them, a filtration method was used by means of an ASF-020 ultrafiltration unit.

In order to determine the optimal ratio of the components of the polyvalent toxoid, all components were combined in the prescribed amount with the addition of a $4 \%$ alumina hydrate gel solution as an adjuvant, saline and thiomersal. The harmlessness, reactogenicity and immunogenicity of the drug were studied in laboratory animals, the live weight of which was: in white mice - 16-18 g, guinea pigs - 350-400 g and rabbits - 2.5-3.2 kg.

\section{Results and discussion}

The cultivation of industrial strains of C.perfringens in flasks and bottles, which was carried out in a certain sequence on a nutrient medium based on liver extract and casein, revealed typical morphological and cultural properties in all samples. Before the inoculation of the microbial culture, a $40 \%$ sterile glucose solution was added to the bottle with the nutrient medium, with the expectation that the final content in the medium was at least $1 \%$ of dry matter. Deep sowing of the microbial culture into the nutrient medium was carried out in a ratio of 10:1, where the optical concentration was not less than $9.0 \times 10^{9}$ cells $/ \mathrm{cm}^{3}$. Then, the bottles were placed in a thermal room with a set temperature of $37 \pm 1^{\circ} \mathrm{C}$, and cultivation was performed for 18 to 32 hours. The result obtained for the cultivation of industrial strains of clostridia are presented in table 1.

Table 1. Cultivation of industrial strains C.perfringens in bottles.

\begin{tabular}{|c|c|c|c|c|c|c|}
\hline \multirow{2}{*}{ No. } & \multirow{2}{*}{ Strains } & \multirow{2}{*}{$\begin{array}{c}\text { Volume } \\
\text { of } \\
\text { nutrient } \\
\text { medium, } \\
1 .\end{array}$} & \multicolumn{2}{|c|}{ Concentration, $\times 10^{9}$ cells $/ \mathrm{cm}^{3}$} & \multirow{2}{*}{$\begin{array}{l}\text { Cultivation } \\
\text { time, h. }\end{array}$} & \multirow{2}{*}{$\begin{array}{l}\mathrm{pH} \text { after the } \\
\text { end of } \\
\text { cultivation }\end{array}$} \\
\hline & & & $\begin{array}{c}\text { At the } \\
\text { beginning of } \\
\text { cultivation }\end{array}$ & $\begin{array}{l}\text { After the end } \\
\text { of cultivation }\end{array}$ & & \\
\hline 1 & C. perfringens type $A$ & 9 & $0.8 \pm 0.5$ & $9.2 \pm 0.01$ & 18 & $6.96 \pm 0.02$ \\
\hline 2 & C. perfringens type $B$ & 9 & $0.8 \pm 0.2$ & $11.0 \pm 0.2$ & 24 & $6.91 \pm 0.05$ \\
\hline 3 & C. perfringens type $C$ & 9 & $0.8 \pm 0.01$ & $10.3 \pm 0.3$ & 22 & $7.15 \pm 1.0$ \\
\hline 4 & C. perfringens type $D$ & 9 & $0.8 \pm 0.01$ & $14.6 \pm 0.2$ & 32 & $7.04 \pm 0.1$ \\
\hline
\end{tabular}

The inoculation of the culture suspension was carried out by introducing into the reactor at least 10 liter of actively growing culture for every 100 liter of the medium. The seeding density of clostridia in the bioreactor was maintained within $800 \pm 50 \times 10^{6} \mathrm{cell} / \mathrm{s} / \mathrm{cm}^{3}$.

After 2-4 hours of cultivation, a glucose solution was added in portions to the reactor so that the final concentration, calculated on dry weight, was $1.0 \%$. This action was carried out for 3-4 hours, fractionally $-0.5 \%$ per hour. At the same time, they controlled the active reaction of the medium, the $\mathrm{pH}$ of which was kept within the range of 6.7-7.2 units. Depending on the intensity of accumulation of microbial cells and the peak of toxin formation, the time of cultivation of anaerobes in the bioreactor took from 16 to $20 \mathrm{~h}$ (Fig. 1). At the end of the cultivation process, the concentration of microbial cells relative to the optical turbidity standard was not less than $8.0 \times 10^{9} \mathrm{cells} / \mathrm{cm}^{3}$. 


\section{C. perfringens type $A-28$}

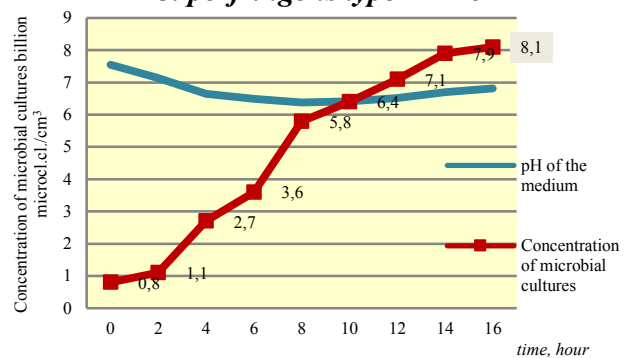

C.perfringens type $C-3$

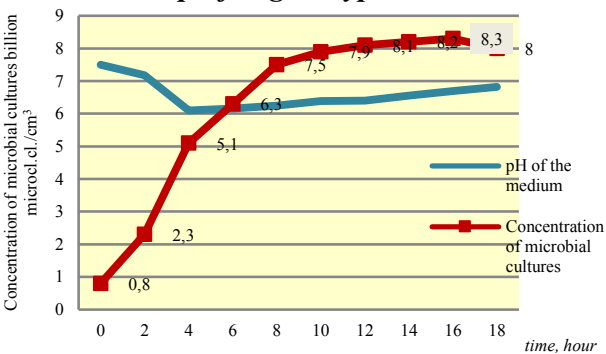

C.perfringens type $B$ - 1

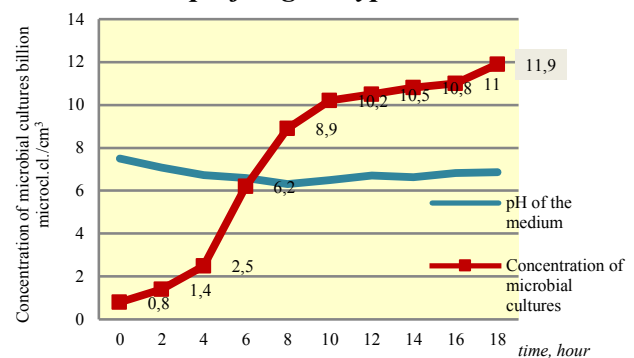

C.perfringens type D - 91

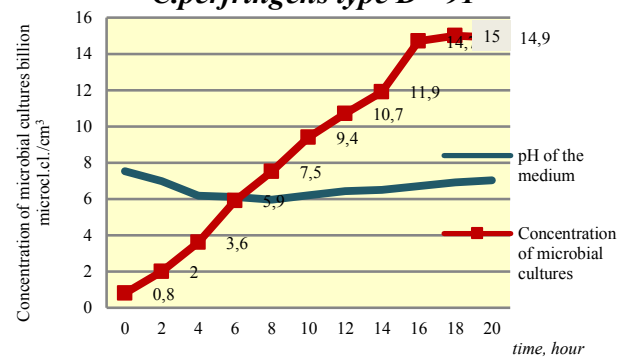

Fig. 1. Dynamics of accumulation of bacterial mass of vaccine strains of C.perfringens types A, B, C and $\mathrm{D}$ in a bioreactor.

According to the accounting, after 16 hours of cultivation, the bacterial mass of C.perfringens type A was $8.1 \times 10^{9}$ cells $/ \mathrm{cm}^{3}$, and the toxicity was $160 \pm 10 \mathrm{Dlm} / \mathrm{cm}^{3}$; in C.perfringens type B, after 18 hours of cultivation, this indicator was $11.9 \times 10^{9} \mathrm{cells} / \mathrm{cm}^{3}$, toxicity $-3500 \pm 100 \mathrm{Dlm} / \mathrm{cm}^{3}$; in C.perfringens type C, after 16 hours the bacterial mass was $8.3 \times 10^{9}$ cells $/ \mathrm{cm}^{3}$, the toxicity was $6500 \pm 200 \mathrm{Dlm} / \mathrm{cm}^{3}$.

The duration of toxin formation in C.perfringens type $\mathrm{D}$, where the bacterial mass was $15.0 \times 10^{9}$ cells $/ \mathrm{cm}^{3}$, was observed after 20 hours. The toxicity index of C.perfringens type D reached $5000 \pm 100 \mathrm{Dlm} / \mathrm{cm}^{3}$.

Concentration of toxins was carried out by filtration in an ultrafiltration unit. Inactivation of toxins was achieved by introducing $0.3-0.5 \%$ formalin, where the formaldehyde content was at least $36 \%$.

To prepare the toxoid, toxins were used that were obtained from the culture liquid with a toxicity of 3000 to $6000 \mathrm{Dlm} / \mathrm{cm}^{3}$, only in C.perfringens type A it was $160 \mathrm{Dlm} / \mathrm{cm}^{3}$. To obtain a monopreparation, each strain was used as an anotoxin, which were used for immunization in rabbits, and after receiving the serum, they were injected into white mice for staging a neutralization reaction. The manifestation of immunogenic activity was noted in the experimental in a volume of $0.2-0.4 \mathrm{~cm}^{3}$, after all the toxoids.

The components of the preparation were designed by selecting the optimal and balanced ratio of toxoids, in particular: C.perfringens type A toxoid - $15 \mathrm{IU} / \mathrm{ml}$, C.perfringens type B - $20 \mathrm{IU} / \mathrm{ml}$, C.perfringens type C - $30 \mathrm{IU} / \mathrm{ml}$, C.perfringens type D - $30 \mathrm{IU} / \mathrm{ml}$, at which the immunized animals were provided with $100 \%$ protection.

Sterile vials, the volume of which was $100 \mathrm{~cm} 3$ with an error of $\pm 3 \%$, with the preparation packaged in them, were sealed with rubber stoppers and, using a special apparatus, were sealed with metal caps.

Sterility control was also carried out. To do this, the sample was sown, at the rate of 0.2$0.3 \mathrm{~cm}^{3}$ in MPB, MPA, agar and Sabouraud broth, two tubes from each medium. After 10 days of observation, sterility was noted in all samples of toxoid inoculations. 
In order to identify the safety of the drug, a mixture of five bottles was injected subcutaneously in the experimental animals in the area of the withers: white mice $-0.5 \mathrm{~cm}^{3}$ each, guinea pigs $-2.0 \mathrm{~cm}^{3}$ each. Observations of the animals showed that during the established 10 days they were active, clinically healthy, and all physiological parameters remained within normal limits. Based on the analysis of the results, it can be concluded that the tested drug is harmless.

Immunogenic activity was determined by intramuscular administration of the drug to 4 rabbits, whose live weight was $2.5-3.0 \mathrm{~kg}$, and the administered dose was $1.5 \mathrm{~cm}^{3}$, with a break of 20-25 days.

Two weeks later, after the introduction of a secondary dose of the drug, blood samples were taken from experimental animals (each rabbit) to obtain serum. Serum obtained from each rabbit was combined in equal parts and mixed. Then, this test was used on white mice as an assessment of the intensity of antitoxic immunity in the reaction of neutralizing toxins.

To determine the neutralization reaction, C.perfringens toxins of types A, B, C, D, with an established activity of $20 \mathrm{Dlm} / \mathrm{cm}^{3}$, were used on white mice weighing from 16 to $18 \mathrm{~g}$.

A total serum sample was placed in $1.5 \mathrm{~cm}^{3}$ in 4 tubes, then solutions of clostridial toxins in a volume of $1.5 \mathrm{~cm}^{3}$ were added to each: in the 1st - C.perfringens type A; in the second - C.perfringens type B; in the third - C.perfringens type C; in the 4th C.perfringens type D.

The resulting mixture of toxins with serum was mixed and left in a thermostat for a period of $45 \mathrm{~min}$ with a set temperature of $37^{\circ} \mathrm{C}$ in order to neutralize the clostridial toxins present in the blood serum with antibodies. After that, each sample of the toxin + serum mixture was intravenously injected into mice in a volume of $0.5 \mathrm{~cm}^{3}$ (in each variant, 5 mice were used).

The observation of the state of the mice after the procedure was carried out for 72 hours. Evaluation of immunogenic activity was carried out by the number of surviving mice, if after the injection of a mixture of toxin with serum 4 out of 5 mice were alive, taking into account at least 4 white mice died in the control variant, then the immunogenic activity was considered high.

Table 2. Results of monitoring the immunogenic activity of toxoid components.

\begin{tabular}{|c|c|c|c|c|c|}
\hline No. & Controlled component & Toxoid dose, $\mathrm{cm}^{3}$ & $\begin{array}{c}\text { Number of } \\
\text { infected } \\
\text { animals }\end{array}$ & $\begin{array}{c}\text { Number of } \\
\text { surviving } \\
\text { animals }\end{array}$ & $\begin{array}{c}\text { \% of surviving } \\
\text { animals }\end{array}$ \\
\hline 1 & C. perfringens type $A$ & $0.5 / 0.5$ & 5 & 4 & 80 \\
\hline 2 & C. perfringens type $B$ & $0.5 / 0.5$ & 5 & 5 & 100 \\
\hline 3 & C. perfringens type $C$ & $0.5 / 0.5$ & 5 & 5 & 100 \\
\hline 4 & C. perfringens type $D$ & $0.5 / 0.5$ & 5 & 5 & 100 \\
\hline 5 & Control animals & Saline $0.5 / 0.5$ & 20 & 0 & 0 \\
\hline
\end{tabular}

The data obtained characterize high immunogenic activity, since the obtained serum from immunized rabbits from 80 to $100 \%$ of white mice infected with control strains of C.perfringens types A, B, C and D in lethal doses survived, and the animals of the control groups all died. The results of the research experiments showed that the use of polyvalent toxoid is an effective way to combat anaerobic enterotoxaemia in animals, since the drug has proven its harmlessness and immunogenicity in relation to all its components.

To determine the optimal immunizing doses of the drug for small and cattle, they were immunized twice with an interval of 21 days with different doses. 14 days after revaccination, the animals were bled, the resulting serum was examined in $\mathrm{pH}$ in white mice.

The results obtained in the course of the study confirmed that the use of this method makes it possible to achieve the optimal immunizing dose for lambs with a double introduction of $0.5-1.0 \mathrm{~cm}^{3}$ and for sheep $-2.0 \mathrm{~cm}^{3}$ of toxoids. For calves, the optimal 
immunizing dose is $3.0 \mathrm{~cm}^{3}$ when injected twice, for pregnant cows and heifers, the inoculation dose is twice injecting $4.0 \mathrm{~cm}^{3}$.

To assess the prophylactic efficacy of polyvalent toxoid, 30 heads of small cattle were selected, from which 36 lambs were subsequently obtained in group 1 and 32 in the second group. Also, 50 head of cattle were selected, from which later 48 calves were received in group 1 and 46 in the second group. The first experimental group of animals was immunized with polyvalent toxoid against anaerobic enterotoxemia of animals. For adult sheep, the drug was administered subcutaneously from the inner side of the thigh, at a dose of $2.0 \mathrm{~cm}^{3}$, twice with a break of 22-25 days, and for lambs up to 6 months old - at a dose of $0.5-1.0 \mathrm{~cm}^{3}$. During the observation of animals after vaccination, no systemic and local complications were noted.

Cows polyvalent toxoid also received a subcutaneous injection into the back third of the neck in a volume of $4.0 \mathrm{~cm}^{3}$, twice with a break of 22-25 days, taking into account that the introduction of the second dose of the drug did not exceed 3-6 weeks before calving. Calves were immunized 14-20 days after birth, also in compliance with the 21 day interval, in a volume of $3.0 \mathrm{~cm}^{3}$. Experimental group II was vaccinated with the ANTOX-9 vaccine against clostridiosis of cattle and small ruminants. Vaccination was carried out according to the instructions for using the drug. In order to assess the effectiveness of the drug, observations of vaccinated animals were carried out throughout the year. The indicator of effectiveness was the incidence of anaerobic enterotoxemia in the study groups.

Analyzing the results of the next 12 months of observation, it should be noted that the incidence of sheep and lambs in the 1 st experimental group was completely absent, that is, $100 \%$ of the animals were healthy, at the same time, in the II experimental group, the incidence was $3.3 \%$, and the safety was $96.7 \%$. In the first experimental group of pregnant cows and heifers, the morbidity was $4 \%$, and the safety $-96.0 \%$, while in the second experimental group, the morbidity was $8 \%$, and the safety was $92 \%, 4$ calves died from anaerobic enterotoxaemia.

The data obtained in the course of the study showed that the polyvalent toxoid produced by us against anaerobic enterotoxemia of young small and cattle is harmless when used. In particular, its advantage lies in the absence of reactogenicity, has a high immunogenic activity, which contributes to the activation of the protective properties of the organism.

\section{Conclusion}

When developing a polyvalent toxoid Clostridium perfringens against anaerobic enterotoxaemia of young cattle and small ruminants, a method of cultivating production strains of clostridia on a nutrient medium based on liver extract and casein-peptone $(\mathrm{g} / \mathrm{l})$ of the following composition has been developed: liver extract - 12.0; casein-peptone - 25.0; $\mathrm{K}_{2} \mathrm{NPO}_{4}-3.2 ; \mathrm{KH}_{2} \mathrm{PO}_{4}-1.8 ; \mathrm{MgSO}_{4}-0.5$. This made it possible to obtain the maximum yield of bacterial mass and toxin formation, where the concentration of microbial cultures was, on average, 8.1-15.0 $\times 10^{9}$ cells $/ \mathrm{cm}^{3}$. Also, confirmation of the harmlessness, areactogenicity of the developed polyvalent toxoid against anaerobic enterotoxaemia of young small and cattle was obtained, which contributes to the development of humoral immunity, which has a pronounced antitoxic effect against strains of C.perfringens.

\section{References}

1. M.R. Ahsani, M.S. Bafti, A.K. Esmailizadeh, M.R. Mohammadabadi, Small Ruminant Research, 95(1), 65-69 (2011) 
2. D.A. Devrishov, F.Kh. Pulotov, Evaluation of the effectiveness of an experimental vaccine against anaerobic enterotoxemia in laboratory and industrial conditions, Materials of the scientific-practical conference TNU. Dushanbe, 133-137 (2020)

3. M.C. Ferrarezi, Anaerobe, 14, 328-331 (2008)

4. M. Gibert, L. Petit, S. Raffestin, A. Okabe, M.R. Popoff, Infection and Immunity, 68, 3848-3853 (2000)

5. AV Kapustin, Kapustin, A.I. Laishevtsev, O.D. Sklyarov, N.S. Abrosimova, RJOAS, 3(63), 170-175 (2017)

6. Yu.N. Kramer, Polyvalent toxoid Clostridium perfringens and its effectiveness in anaerobic enterotoxemia in calves, 20 (Moscow, 2020)

7. E. Kovaleva, RJOAS, 7(2), 247-249 (2016)

8. M. Lebrun, A. Linden, J.G. Mainil, Veterinary Record, 167, 13-22 (2010)

9. C.J. Lewis, Veterinary Clinics of North America, 27(1), 121-126 (2011)

10. A. Mojtaba, G. Mehdi, D. Hamid, Genetics and Evolution, 40, 282-287 (2016)

11. A. Mojtaba, G. Mehdi, E. Majid, Research in Veterinary Science, 115, 332-339 (2017)

12. A.Kh. Mumtaz, B. Sher, U. Naimat, U. Sana, I. Muhammad, Small Ruminant Research, 173, 70-73 (2019)

13. F.Kh. Pulotov., D.A. Devrishov, I.A. Ismatov, Problems of Biology of Productive Animals, 1, 34-43 (2020)

14. F.Kh. Pulotov, Improving the technology of manufacturing a polyvalent vaccine against clostridiosis of animals, 19 (Moscow, 2020)

15. L.M. Redondo, M. Farber, A. Venzano, B.H. Jost, M.E. Fernandez-Miyakawa, Anaerobe, 20, 1-4 (2013)

16. S. Sayeed, F.A. Uzal, D.J. Fisher, Molecular Microbiology, 67, 15-30 (2008)

17. O.D. Sklyarov, A.V. Kapustin, A.I. Laishevtsev, A.M. Gulyukin, Russian veterinary journal, 1, 20-23 (2017)

18. F.A. Uzal, Journal of Veterinary Diagnostic Investigation, 20, 253-265 (2008)

19. F.A. Uzal, Infection and Immunity,77(12), 5291-5299 (2009)

20. P.J. Watson S.F., Scholes, Veterinary Record, 164, 816-818 (2009)

21. F. Yadegar, P. Nakhaei, Gh. Hashemtabar, Gh. Kalidari, J. Razmyar, Small Ruminant Research, 168, 1-5 (2018) 